\title{
Nanoparticles of carbon allotropes inhibit glioblastoma multiforme angiogenesis in ovo
}

This article was published in the following Dove Press journal:

International Journal of Nanomedicine

24 November 201I

Number of times this article has been viewed

\section{Marta Grodzik' \\ Ewa Sawosz' \\ Mateusz Wierzbicki ${ }^{1}$ \\ Piotr Orlowskil \\ Anna Hotowy ${ }^{2}$ \\ Tomasz Niemiec' \\ Maciej Szmidt ${ }^{3}$ \\ Katarzyna Mitura ${ }^{4}$ \\ André Chwalibog ${ }^{2}$ \\ 'Division of Biotechnology and Biochemistry of Nutrition, Warsaw University of Life Sciences, \\ Warsaw, Poland; ${ }^{2}$ Department of Basic Animal and Veterinary Science, University of Copenhagen, Copenhagen, Denmark; ${ }^{3}$ Division of Histology and Embryology, Warsaw University of Life Sciences, Warsaw. Poland; ${ }^{4}$ Department of Biomedical Engineering, Koszalin University of Technology, Koszalin, Poland}

Correspondence: André Chwalibog University of Copenhagen, Department of Basic Animal and Veterinary Sciences, Groennegaardsvej 3, 1870

Frederiksberg, Denmark

Tel +453533 3044

Fax+453533 3020

Email ac@life.ku.dk
Abstract: The objective of the study was to determine the effect of carbon nanoparticles produced by different methods on the growth of brain tumor and the development of blood vessels. Glioblastoma multiforme cells were cultured on the chorioallantoic membrane of chicken embryo and after 7 days of incubation, were treated with carbon nanoparticles administered in ovo to the tumor. Both types of nanoparticles significantly decreased tumor mass and volume, and vessel area. Quantitative real-time polymerase chain reaction analysis showed downregulated fibroblast growth factor- 2 and vascular endothelial growth factor expression at the messenger ribonucleic acid level. The present results demonstrate antiangiogenic activity of carbon nanoparticles, making them potential factors for anticancer therapy.

Keywords: cancer, nanoparticle, embryo, angiogenesis, $F G F-2$, VEGF

\section{Introduction}

Glioblastoma multiforme (GBM) is one of the most common tumors of the central nervous system. GBM grows in the brain, where it develops extensive tumors with specific infiltration along nerve fibers, somas, pia mater, and blood vessels. This prevents the total resection of the tumor. Glioblastoma is characterized by high proliferation of cancer cells, increased cellularity, necrosis, and a high potential for new blood vessels to develop from the vessels that already exist (angiogenesis). ${ }^{1-3}$ Angiogenesis is the main reason for the transformation of the small local lesions into extensive metastatic tumors. ${ }^{4}$ The intensity of new blood vessel formation depends on the balance between proangiogenic factors, such as basic fibroblast growth factor-2 $(F G F-2)$, vascular endothelial growth factor $(V E G F)$, and antiangiogenic factors, such as angiostatin, angiopoietin 2, and endostatin. Shifting of this equilibrium due to the increased expression of antiangiogenic or reduction of proangiogenic factors inhibits angiogenesis. ${ }^{5-8}$ Inhibition of tumor angiogenesis suppresses tumor growth and prevents metastasis, and is a key target in cancer therapy. ${ }^{9}$ There have been several trials of angiogenic therapy applied to different places of cancer formation (breast, prostate, colon, liver, or kidney), ${ }^{10-14}$ as well as in the brain. ${ }^{15,16}$ Most utilize VEGF (VEGF-A and $V E G F-B)$ or $V E G F$ receptor (VEGFR1-3, $P D G F R \beta$, and c-Kit) inhibition, ${ }^{17-20}$ while some also block pathways not dependent on VEGF (CD36 receptor, FGF pathway, cyclooxygenase-2, and hypoxia-inducible factors $1 \alpha)^{21-23}$ or inhibit endothelial cell migration (integrins $\alpha v \beta 1, \alpha v \beta 3, \alpha v \beta 5$ ). ${ }^{24}$ However, up to now, only bevacizumab, containing antiVEGF antibodies, has entered phase III clinical trials for treating GBM. ${ }^{25}$ 
Recently, new biologically active substances have appeared that can be useful in antiangiogenic therapy: nanoparticles of carbon allotropes. They are not only biocompatible but also bioactive, inhibiting lipid peroxidation and regulating the expression of genes associated with cellular, genotoxic, and oxidative stress. ${ }^{26,27}$ Anticancer properties are characteristic for water-soluble C60 fullerenes. They inhibit growth of Lewis lung carcinoma tumors in mice, probably by inhibiting specific receptors (eg, endothelial growth factor receptor). ${ }^{28}$ In anticancer therapy, allotropic forms of carbon are also applied as a drug delivery system. Conjugate water-soluble single-walled nanotube-palitaxel ${ }^{29}$ and single-walled nanotube-doxorubicin ${ }^{30}$ enhance permeability and retention in xenograft tumors, while not changing the effect of the medical treatment. Murugesan et $\mathrm{al}^{31}$ proved the antiangiogenic properties of graphite nanoparticles, multi-walled carbon nanotubes, and C60 fullerenes on the blood vessels of chicken chorioallantoic membrane. They resulted from the binding of the proangiogenic factors $F G F-2$ or $V E G F$. Results of experiments on embryonic chicken heart have also showed that diamond and graphite nanoparticles downregulate FGF-2 expression. ${ }^{32}$ There are no data concerning the influence of carbon nanoparticles on the development of blood vessels in GBM tumors.

It was hypothesized that the investigated carbon nanoparticles can downregulate the expression of factors associated with the formation of new blood vessels in GBM tumors. The objective of the study was to determine the effect of carbon nanoparticles manufactured by different methods on the growth of brain tumor and the development of its blood vessels.

\section{Materials and methods Carbon nanoparticles}

Nanoparticles of carbon allotropes: ultradispersed detonation diamond (UDD) and microwave-radiofrequency (MW-RF) carbon allotrope, were obtained from the Technical University of Lodz (Lodz, Poland). UDD were produced by the detonation method described by Danilenko. ${ }^{33} \mathrm{MW}-\mathrm{RF}$ was synthesized by a plasma-assisted chemical vapor deposition process using the dual frequency method ${ }^{34}$ in MW (2.45 GHz) and RF (13.56 MHz) plasma in methane under a pressure of $100 \mathrm{~Pa}$. The structure of nanoparticles and electron diffraction patterns were visualized by JEM2000EX transmission electron microscope at $200 \mathrm{kV}$ (JEOL Ltd, Tokyo, Japan). Transmission electron microscope images of UDD and MW-RF nanoparticles and electron diffraction patterns are presented in Figures 1 and 2, showing differences in the phase content and size of the particles. The size of the nanoparticles ranged from 2-10 nm for UDD and 30-100 nm for MW-RF.

Infrared spectroscopy was used to detect the vibrational modes of the nanoparticles and, in particular, to reveal their surface termination. Fine potassium bromide powder and sample mixture at the ratio of $300: 1 \mathrm{mg}$ were used to prepare a pellet in the hydraulic press under a 10-ton pressure. Fourier transform infrared spectra were registered in the classic mid-infrared range $\left(4000-400 \mathrm{~cm}^{-1}\right)$ with a

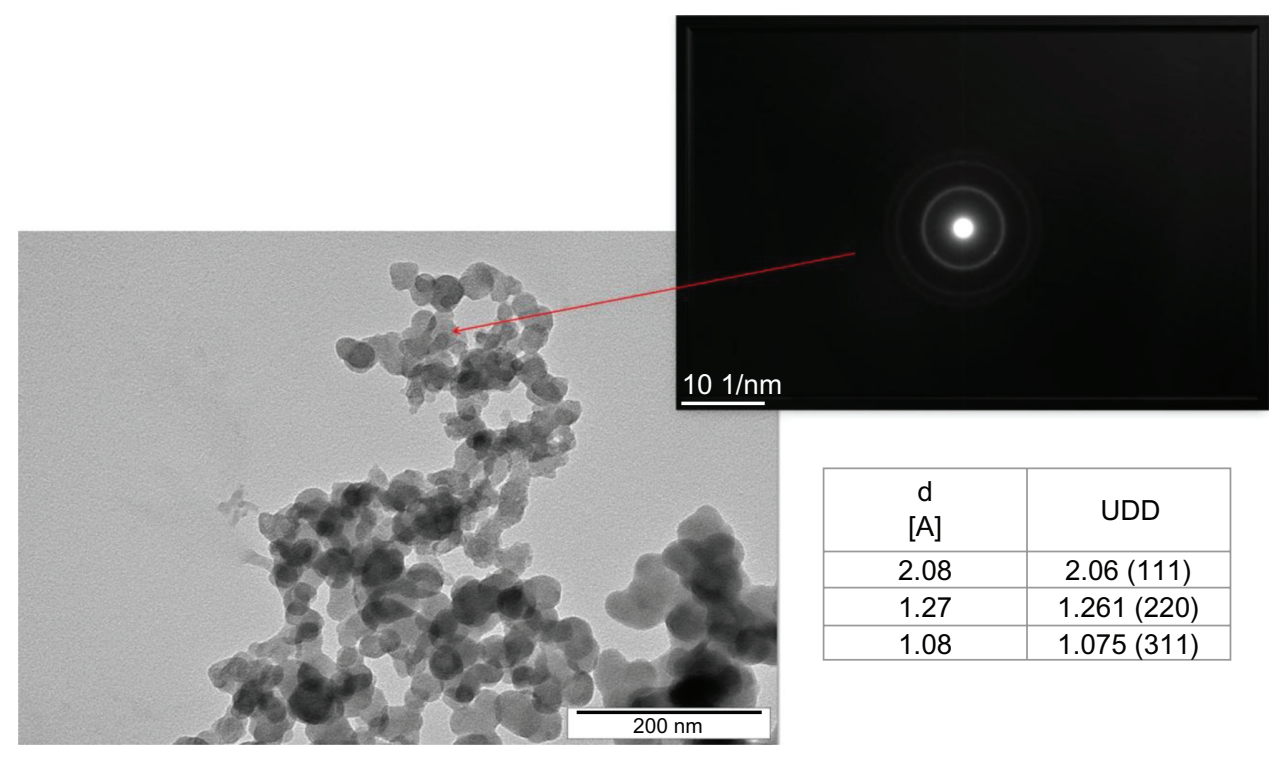

Figure I Transmission electron microscope images and electron diffraction pattern of ultradispersed detonation diamond (UDD) nanoparticles. 


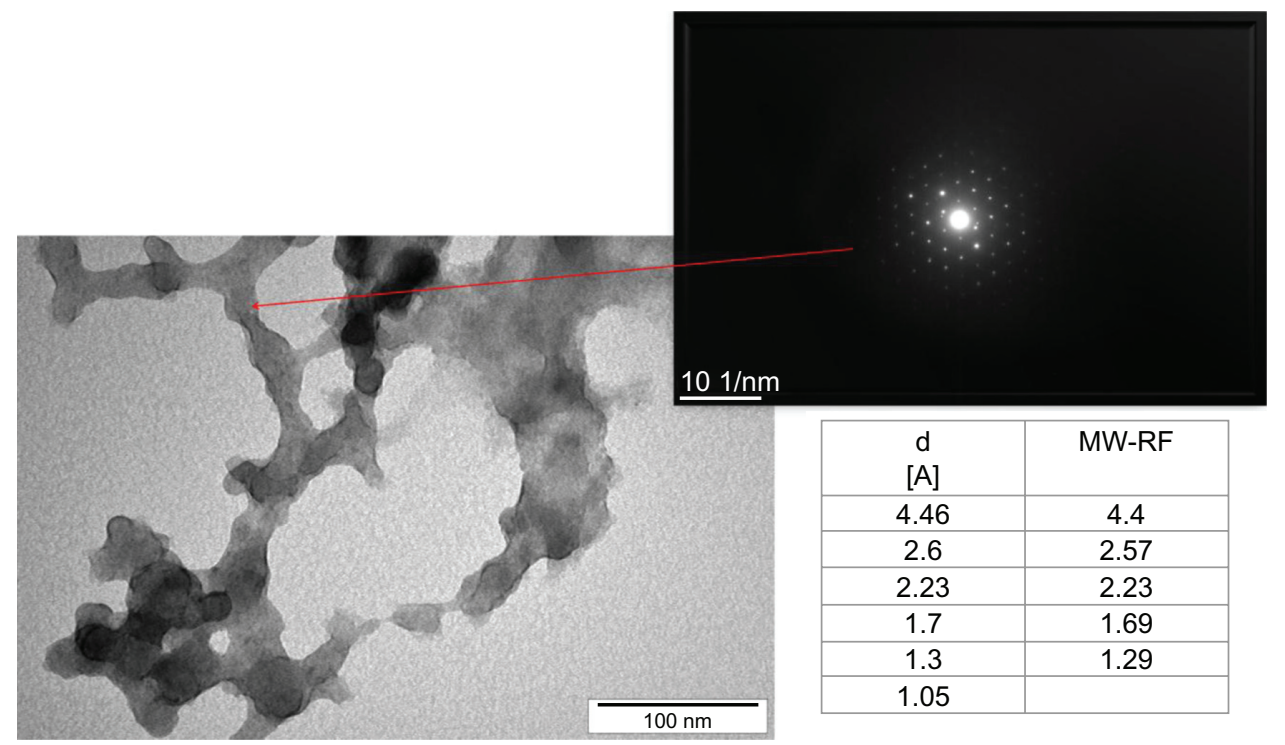

Figure 2 Transmission electron microscope images and electron diffraction pattern of microwave-radiofrequency (MW-RF) carbon nanoparticles.

resolution of $4 \mathrm{~cm}^{-1}$. A pellet of pure potassium bromide was used as the background. Twenty-five scans were collected to obtain a spectrum for each sample using a PerkinElmer System 2000 spectrometer (Applied Biosystems, Inc, Foster City, CA), operated by Grams 2000 software (PerkinElmer, Inc, Waltham, MA). The Fourier transform infrared spectra of UDD and MW-RF nanoparticles are shown in Figure 3. The measurements confirmed the chemical structures of the nanoparticles and indicated that the UDD nanoparticle had a surface termination at the carbonyl and carbon-oxygen polar groups, while the MW-RF nanoparticle had surface terminations at the carbon-hydrogen group.

Zeta potential of hydrocolloids of nanoparticles was measured by light scattering method, using Zetasizer Nano ZS (ZEN3500; Malvern Instruments, Malvern, Worcestershire, United Kingdom). Each sample was measured after 120 seconds of stabilization at $25^{\circ} \mathrm{C}$ (20 replicates). Zeta potential of UDD nanoparticles hydrosol was +15 and MW-RF nanoparticles hydrosol was -19.3 .

In Table 1, there is a summary of the physical and chemical characteristics of UDD and MW-RF nanoparticles.

\section{Cells and embryos}

Human U87 glioblastoma cells (HTB-14; American Type Culture Collection, Manassas, VA) were maintained in Dulbecco's modified Eagle medium (Sigma-Aldrich Corporation, St Louis, MO) with 10\% fetal bovine serum (Sigma-Aldrich). The fertilized eggs (Gallus gallus) $(\mathrm{n}=60)$ were supplied by a commercial hatchery (Debowka, Poland).

\section{Culture of GBM on chorioallantoic membrane}

After 6 days of egg incubation, the silicone ring with the deposited $3-4 \times 10^{6} \mathrm{U} 87$ cells suspended in $30 \mu \mathrm{L}$ of culture medium was placed on the chorioallantoic membrane. The eggs were incubated for 7 days and then 36 eggs with visible tumor development were chosen. Eggs were divided into three groups of twelve: the control group, UDD group (injected with $200 \mu \mathrm{L}$ of $500 \mu \mathrm{g} / \mathrm{mL}$ solution of UDD), and MW-RF group (injected with $200 \mu \mathrm{L}$ of $500 \mu \mathrm{g} / \mathrm{mL}$ solution of MW-RF). The solutions were added directly into the tumors. After 2 days, the tumors were resected for further analysis.

\section{Calculation of volume of tumor and blood vessel area}

Digital photos of tumors were taken by a stereo microscope (SZX10, CellD software version 3.1; Olympus Corporation, Tokyo, Japan). The measurements were taken with cellSens Dimension Desktop version 1.3 (Olympus). The tumor volumes were calculated with the equation:

$$
\mathrm{V}=\frac{4}{3} \pi \mathrm{r}^{3} \quad \text { where } \quad \mathrm{r}=\frac{1}{2} \sqrt{\text { diameter }_{1} \times \text { diameter }_{2}}
$$

Measurement of the blood vessel area was performed in accordance with Seidlitz et al. ${ }^{35}$ On each of the analyzed images of the tumor, five different areas of a fixed size of $400 \mu \mathrm{m}^{2}$ were marked. The fragments with large blood vessels were not chosen. All the image pixels in shades of red, 

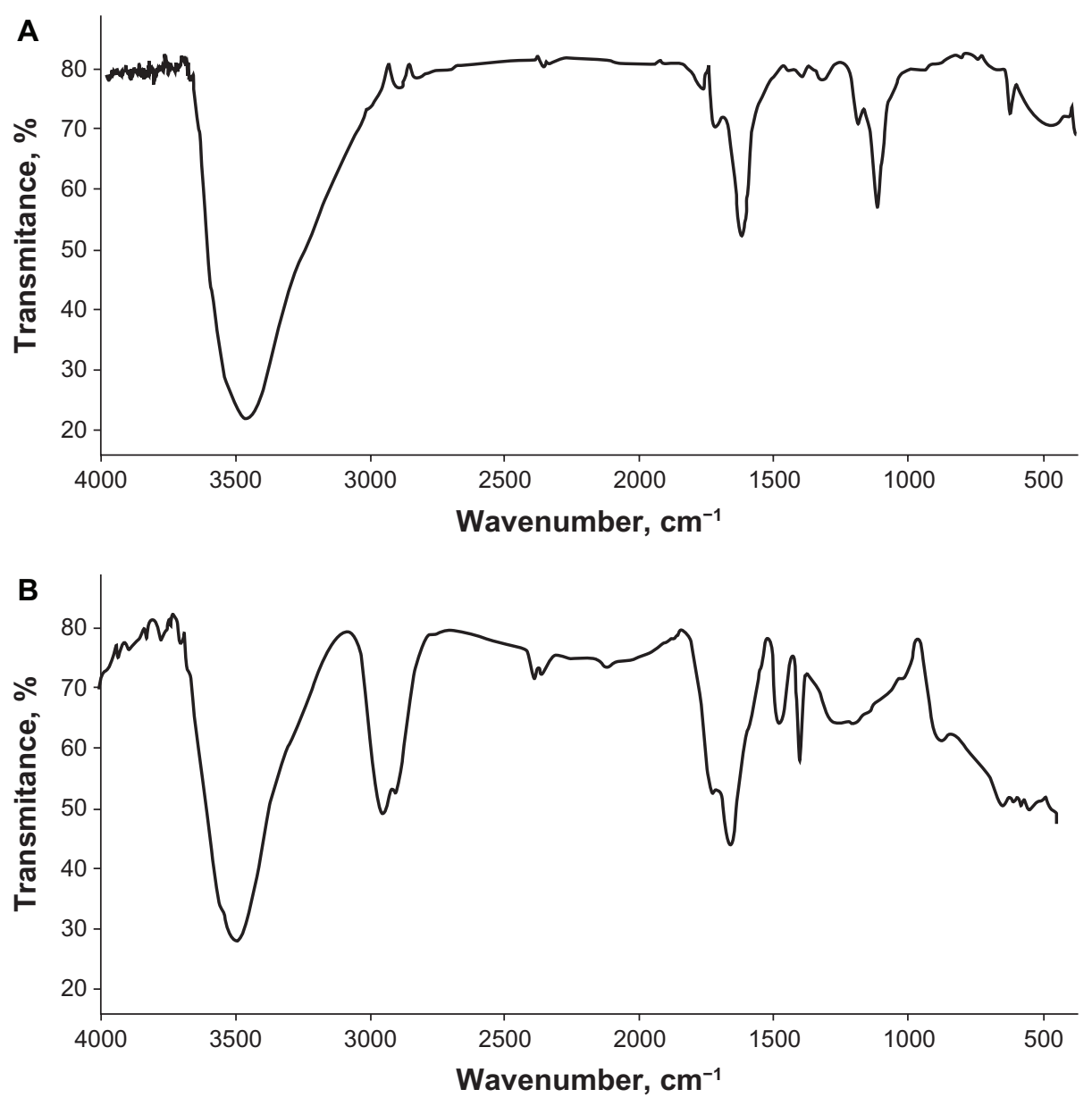

Figure 3 Fourier transform infrared spectra of ultradispersed detonation diamond (A) and microwave-radiofrequency carbon (B) nanoparticles.

after strengthening of the picture contrast, were converted into the black pixels and counted. The result is a percentage count, in relation to all pixels in the analyzed field.

\section{Histology analysis}

After resection, the tumors were placed into $10 \%$ buffered formaldehyde (Sigma-Aldrich). Samples were embedded in paraffin (Paraplast ${ }^{\circledR}$; Sigma-Aldrich) and cut into 5- $\mu \mathrm{m}$ sections. After staining with Harris hematoxylin (POCH

Table I Physical and chemical characteristics of ultradispersed detonation diamond (UDD) and microwave-radiofrequency (MW-RF) carbon nanoparticles

\begin{tabular}{lll}
\hline & $\begin{array}{l}\text { UDD } \\
\text { nanoparticle }\end{array}$ & $\begin{array}{l}\text { MW-RF } \\
\text { nanoparticle }\end{array}$ \\
\hline Production & Detonation method & Microwave method \\
Size $[\mathrm{nm}]$ & $2-10$ & $30-100$ \\
Atom configuration & $\mathrm{sp} 3$ & $\mathrm{sp} 2$ \\
Surface termination & $\mathrm{C}=\mathrm{O}, \mathrm{C}-\mathrm{O}$ & $\mathrm{C}-\mathrm{H}$ \\
Zeta potential & +15 & -19.3 \\
\hline
\end{tabular}

Abbreviations: $\mathrm{C}$, carbon; $\mathrm{H}$, hydrogen; $\mathrm{O}$, oxygen.
S.A, Gliwice, Poland) and eosin (BDH Laboratory Supplies, Poole, Dorset, United Kingdom), the samples were analyzed by light microscopy (DM750; Leica Microsystems GmbH, Wetzlar, Germany) using LAS EZ version 2.0 software (Leica) (Figure 5).

\section{Quantitative real-time polymerase chain reaction analysis}

Total ribonucleic acid (RNA) from tumor tissue was obtained using SV Total RNA Isolation System (Promega Corporation, Madison, WI). Total RNA ( $2 \mu \mathrm{g})$ was reverse-transcribed using reverse transcriptase (Promega), oligodeoxythymidylic acid, and random primers (TAG Copenhagen A/S, Copenhagen, Denmark). Relative messenger RNA levels of FGF-2 (locus NC_006091), VEGF (locus NC_006090), and the housekeeping gene EEF1A2 (locus NC_006107) were determined by real-time polymerase chain reaction using a LightCycler ${ }^{\circledR} 480$ SYBR Green I Master and LightCycler $^{\circledR} 480$ Real-Time Polymerase Chain Reaction System (Roche Diagnostics GmbH, Mannheim, Germany), which 
was programmed for an initial step of 5 minutes at $95^{\circ} \mathrm{C}$ followed by 45 cycles of 10 seconds at $95^{\circ} \mathrm{C}, 10$ seconds at $60^{\circ} \mathrm{C}$, and 9 seconds at $72^{\circ} \mathrm{C}$. The oligonucleotides used as specific primers were: 5'GGCACTGAAATGTGCAACAG3' and 3'TCCAGGTCCAGTTTTTGGTC5' for FGF-2; 5'TGA GGGCCTAGAATGTGTCC3' and 3'TCTTTTGACC CTTCCCCTTT5' for VEGF; and 5'AGCAGACTTT GTGACCTTGCC3' and 3'TGACATGAGACAGACG GTTGC5' for EEF1A2. All the reactions were performed in triplicate.

\section{Statistical analysis}

Results were expressed as mean and standard error. The data were analyzed using monofactorial analysis of variance and the differences between groups were tested by Duncan's multiple range tests, using STATGRAPHICS ${ }^{\circledR}$ Plus 4.1 (StatPoint Technologies, Inc, Warrenton, VA). Differences with $P<0.05$ were considered significant.

\section{Results}

Analysis of the antiangiogenic features of carbon nanoparticles (UDD and MW-RF) in terms of the growth of brain GBM tumors and their blood vessels was performed in ovo on the chicken embryo experimental model.

Tumor weight, volume, blood vessel area, and FGF-2 and $V E G F$ expression levels were assessed. A decrease in tumor growth in terms of its weight and volume was observed in both treated groups (Table 2). In the UDD group, the weight was reduced by $73 \%$ and the volume by $61 \%$, and in the MW-RF group, the weight decreased by $69 \%$ and the volume by $68 \%$ compared to the control group $(P<0.05)$.

A decrease in blood vessel area was detected in the UDD and MW-RF groups versus the control group (Table 2). In the control group, $58 \%$ area of vessels was detected on average, but $19 \%$ and $25 \%$ in the UDD and MW-RF groups was detected, respectively. Except for the decreased blood vessel

Table 2 Weight, volume, and area of blood vessels of glioblastoma tumors

\begin{tabular}{|c|c|c|c|c|c|}
\hline \multirow[t]{2}{*}{ Parameters } & \multicolumn{3}{|l|}{ Groups } & \multicolumn{2}{|l|}{ ANOVA } \\
\hline & Control & UDD & MW-RF & SE-pooled & $P$ value \\
\hline Weight (mg) & $546^{a}$ & $145^{b}$ & $169^{b}$ & 101.9 & 0.017 \\
\hline Volume $\left(\mathrm{mm}^{3}\right)$ & $106.1^{\mathrm{a}}$ & $41.5^{b}$ & $33.7^{\mathrm{b}}$ & 15.95 & 0.011 \\
\hline Vessels' area (\%) & $58.3^{a}$ & $18.5^{b}$ & $24.7^{b}$ & || $.5 \mid$ & 0.035 \\
\hline
\end{tabular}

Note: ${ }^{a, b}$ Values within rows with different superscripts are significantly different, $P<0.05$.

Abbreviations: ANOVA, analysis of variance; MW-RF, microwave-radiofrequency carbon nanoparticles; SE, standard error; UDD, ultradispersed detonation diamond. d nanoparticles. density after UDD and MW-RF treatment, characteristic changes in the macroscopic images of the observed blood vessels were found (Figure 4). In the control group, distinctive blood vessel branching was observed; however, in the UDD and MW-RF groups, only the fragments of blood vessels and hemorrhagic processes were seen.

In the histology of GBM between the control (Figure 5A and B), UDD (Figure 5C and D), and MW-RF (Figure 5E and F)
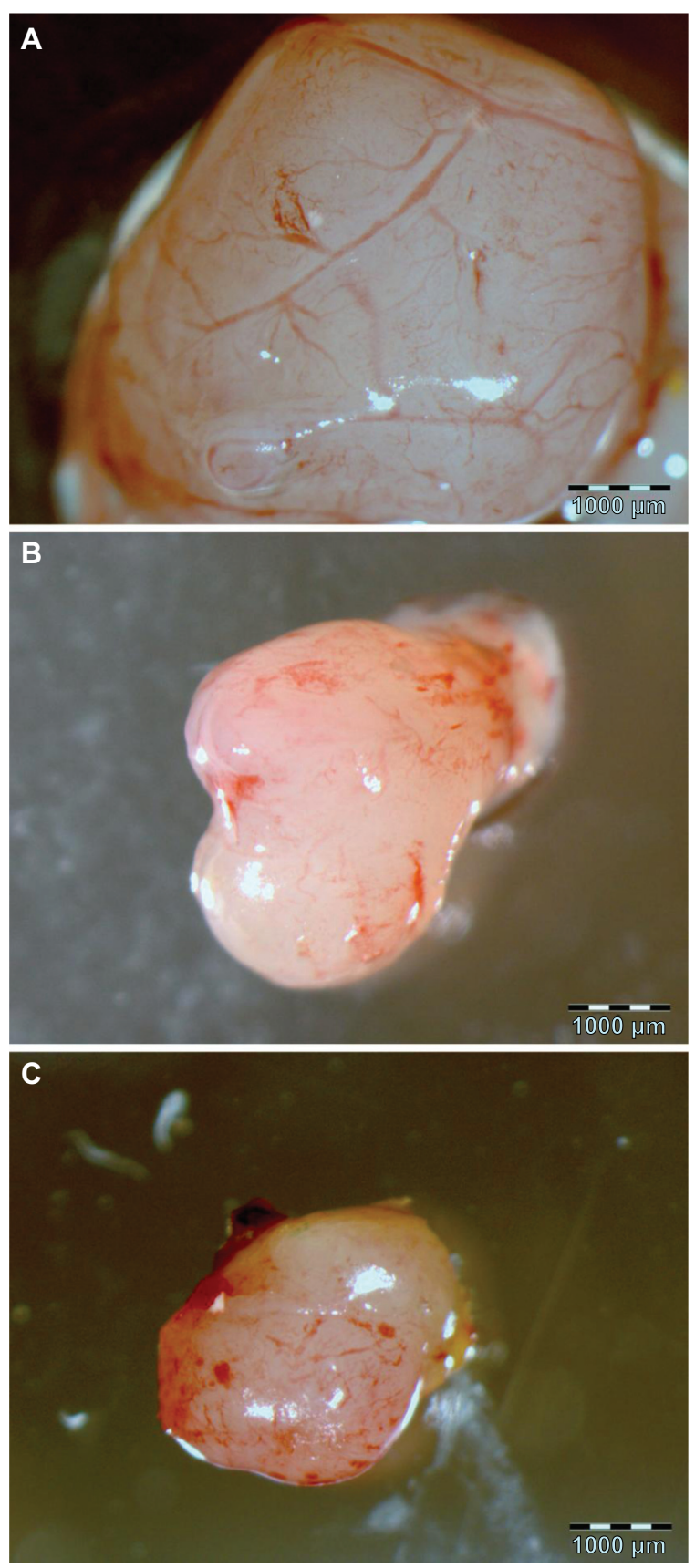

Figure 4 Images of a glioblastoma multiforme tumor cultured on chorioallantoic membrane: (A) control group, (B) ultradispersed detonation diamond group, and (C) microwave-radiofrequency group.

Note: Scale bar: $1000 \mu \mathrm{m}$. 

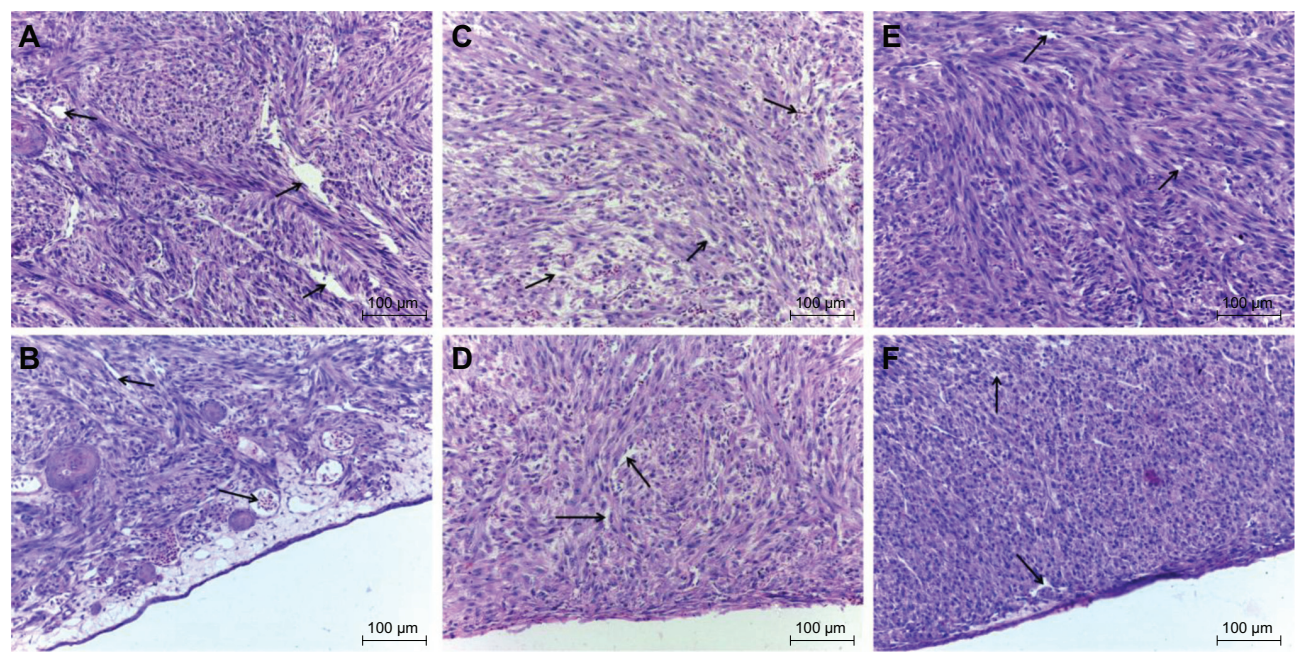

Figure $\mathbf{5}$ Histology of glioblastoma multiforme tumor cultured on chorioallantoic membrane: (A, B) control group, (C, D) ultradispersed detonation diamond group, and (E, F) microwave-radiofrequency group.

Notes: Scale bar: $100 \mu \mathrm{m}$. The images in (A), (C), and (E) were taken from the central part of the tumor, while those in (B), (D), and (F) from near its surface. Arrows point to blood vessels.

groups, strong differences were noticed. Chicken chorioallantoic membrane surrounding the tumor in the control group was thick with strong vascularity, while in the UDD and MW-RF groups, it was thin without any blood vessels. In the central part of the tumor in all the groups, fewer blood vessels were found than in the lateral part in contact with the host.

In the control group, the diameter of blood vessels varied between $2-30 \mu \mathrm{m}$, with a wide, transparent, and well-defined lumen. In the UDD and MW-RF groups, the blood vessels had similar dimensions as the capillary vessels $(2-7 \mu \mathrm{m})$, while the lumen was irregular, narrow, and chink-like shaped. Endothelial cells of blood vessels in the control group had a typical shape with a flattened nucleus. In the UDD and MW-RF groups, endothelial cells had tube-like shapes and their nuclei were round. In these groups, there were also a lower number of blood vessels compared with the control group, with erythrocytes being present between the parenchymal cells of the tumor and necrotic area.

Table 3 shows the results of the transcription of messenger RNA encoding $F G F-2$ and $V E G F$. There was a $69 \%$ decrease in $F G F-2$ expression in the UDD group compared to the control group $(P<0.05)$. A decrease of $33 \%$ was observed in the MW-RF group, but this was not significant. The amount of $V E G F$ gene transcripts was also reduced in the UDD (by $72 \%$ ) and MW-RF (by 48\%) groups compared to the control $(P<0.05)$.

\section{Discussion}

UDD and MW-RF nanoparticles reduced tumor mass and volume and inhibited new blood vessel development in
GBM tumors cultured in ovo. It was observed that UDD nanoparticles significantly decreased $F G F-2$ and $V E G F$ expression, while MW-RF nanoparticles only reduced $V E G F$ expression, although there was a tendency of reduced $F G F-2$ expression too. $V E G F$ is one of the most important factors influencing angiogenesis. The $V E G F$ family ( $V E G F-A, V E G F-B, V E G F-C, V E G F-D, V E G F-E$, and placenta growth factor) is activated at different stages of the angiogenic cascade, including the induction of endothelial cell formation and proliferation, as well as stimulation of endothelial nitric oxide synthase. ${ }^{36}$ The increased protein level of $V E G F$ is linked to the higher permeability of the blood vessels and their untypical structure, which is characteristic of tumors. ${ }^{37}$ Lowering of the VEGF level contributes to the normalization of blood vessels, facilitating the infiltration of other factors (eg, drugs) into the tumor, ${ }^{38}$ while inhibiting $V E G F$ expression limits the transport of nutrients into cancer cells. ${ }^{39}$ In the present study, erythrocytes were observed

Table 3 Fibroblast growth factor-2 (FGF-2) and vascular endothelial growth factor (VEGF) gene expression profile in glioblastoma tumors following ultradispersed detonation diamond (UDD) and microwave-radiofrequency (MW-RF) treatment

\begin{tabular}{|c|c|c|c|c|c|}
\hline \multirow{2}{*}{$\begin{array}{l}\text { Level of mRNA } \\
\text { expression }\end{array}$} & \multicolumn{3}{|l|}{ Groups } & \multicolumn{2}{|l|}{ ANOVA } \\
\hline & Control & UDD & MW-RF & SE-pooled & $P$ value \\
\hline FGF-2/EEFIA2 & $1.1216^{a}$ & $0.346^{b}$ & $0.754^{\mathrm{a}}$ & 0.2245 & 0.024 \\
\hline VEGF/EEFIA2 & $2.1 I^{a}$ & $0.593^{b}$ & $\mathrm{I} .098^{\mathrm{c}}$ & 0.3960 & 0.021 \\
\hline
\end{tabular}

Notes: a,b,c Values within rows with different superscripts are significantly different, $P<0.05$. Values were normalized to the housekeeping gene EEFIA2.

Abbreviations: ANOVA, analysis of variance; mRNA, messenger ribonucleic acid; SE, standard error. 
to flow out to the parenchyma and necrotic area in tumors from the UDD and MW-RF groups. The occurrence of this process, in association with decreased levels of VEGF and $F G F$, indicates a breakdown and/or disappearance of blood vessels.

There are many possible mechanisms of action of carbon nanoparticles (UDD and MW-RF). The most probable seems to be the one described by Murugesan et $\mathrm{al}^{31}$ who showed that multi-walled carbon nanotubes, $\mathrm{C} 60$ fullerenes, and graphite nanoparticles inhibited angiogenesis when $V E G F$ and $F G F-2$ levels were elevated. Such a case takes place in the tumor microenvironment, where the level of proangiogenic factors is higher than that in healthy tissues. Carbon nanoparticles can bind to $V E G F$ and $F G F-2$ or their receptors and in this way influence signal transduction between cells. The possibility of connecting the factors influencing angiogenesis is the property of carbon nanoparticles, but this has also been observed in experiments with nanosilver ${ }^{40-42}$ and nanogold. ${ }^{43-46}$ Nanosilver inhibits the phosphorylation of phosphatidylinositol-3-kinase/Akt at serine 473, leading to the inhibition of $V E G F$-induced angiogenesis. ${ }^{41}$ Nanogold, by binding VEGF165 (a heparin-binding growth factor), inhibits its action and lowers the level of proliferation. ${ }^{43}$ Moreover, mixing nanogold and nanosilver with heparan sulfate enhances heparan binding to $F G F-2$ and $V E G F$ because silver and gold nanoparticles can both bind to amines and thiol groups. ${ }^{47}$

The presence of different functional groups on the surface of UDD and MW-RF nanoparticles is probably the reason that although the effect of UDD and MW-RF nanoparticles is comparable (decrease of the weight and volume of the tumor as well as the number and area of the vessels), the mode of action is not identical (UDD nanoparticles inhibit $V E G F$ and $F G F-2$, while MW-RF nanoparticles inhibit only $V E G F$ [Table 3]). This may be the result of different physical and chemical properties of the nanoparticles (Table 1). They differ not only in the way they are manufactured but also in size, zeta potential, atomic configuration, and surface termination. Due to the different functional groups on the surface, nanoparticles can bind different domains of proangiogenic factors or their receptors. It is interesting to note that despite different physicochemical features, both carbon nanoparticles exhibited antiangiogenic properties, but their intensity of action differed.

Regardless of the unclear mechanism of carbon nanoparticle activity, their biocompatibility together with the present results demonstrating their antiangiogenic properties make them potential factors for anticancer therapy.

\section{Acknowledgments}

This work was supported by the following grants: "New, multifunctional nanopowder of carbon" 357/ERA-NET 2008-2011 and Danish Agency for Science Technology and Innovation \#2106-08-0025. The report is part of Marta Grodzik's doctoral thesis.

\section{Disclosure}

The authors report no conflicts of interest in this work.

\section{References}

1. Ricci-Vitiani L, Pallini R, Biffoni M, et al. Tumour vascularization via endothelial differentiation of glioblastoma stem-like cells. Nature. 2010;468(7325):824-828.

2. Salacz ME, Watson KR, Schomas DA. Glioblastoma: part I. Current state of affairs. Mo Med. 2011;108(3):187-194.

3. Chen J, Kesari S, Rooney C, et al. Inhibition of notch signaling blocks growth of glioblastoma cell lines and tumor neurospheres. Genes Cancer. 2010;1(8):822-835.

4. Carmeliet P. Angiogenesis in life, disease and medicine. Nature. 2005; 438(7070):932-936.

5. Hillen F, Griffioen AW. Tumour vascularization: sprouting angiogenesis and beyond. Cancer Metastasis Rev. 2007;26(3-4):489-502.

6. Reijneveld JC, Voest EE, Taphoorn MJ. Angiogenesis in malignant primary and metastatic brain tumors. $J$ Neurol. 2000;247(8):597-608.

7. Brekken RA, Thorpe PE. Vascular endothelial growth factor and vascular targeting of solid tumors. Anticancer Res. 2001;21(6B):4221-4229.

8. Folkman J. Angiogenesis in cancer, vascular, rheumatoid and other disease. Nat Med. 1995;1(1):27-31.

9. Puduvalli VK, Sawaya R. Antiangiogenesis - therapeutic strategies and clinical implications for brain tumors. $J$ Neurooncol. 2000;50(1-2): 189-200.

10. Im SA, Kim JS, Gomez-Manzano C, et al. Inhibition of breast cancer growth in vivo by antiangiogenesis gene therapy with adenovirusmediated antisense-VEGF. Br J Cancer. 2001;84(9):1252-1257.

11. Hartley-Asp B, Vukanovic J, Joseph IB, Strandgården K, Polacek J, Isaacs JT. Anti-angiogenic treatment with linomide as adjuvant to surgical castration in experimental prostate cancer. J Urol. 1997;158(3 Pt 1): 902-907.

12. Murata K, Moriyama M. Isoleucine, an essential amino acid, prevents liver metastases of colon cancer by antiangiogenesis. Cancer Res. 2007; 67(7):3263-3268

13. Zhang Y, Jiang X, Qin X, et al. RKTG inhibits angiogenesis by suppressing MAPK-mediated autocrine VEGF signaling and is downregulated in clear-cell renal cell carcinoma. Oncogene. 2010;29(39):5404-5415.

14. Jie S, Li H, Tian Y, et al. Berberine inhibits angiogenic potential of Hep G2 cell line through VEGF down-regulation in vitro. J Gastroenterol Hepatol. 2011;26(1):179-185.

15. Brem S, Grossman SA, Carson KA, et al. Phase 2 trial of copper depletion and penicillamine as antiangiogenesis therapy of glioblastoma. Neuro Oncol. 2005;7(3):246-253.

16. Zhou YX, Huang YL. Antiangiogenic effect of celastrol on the growth of human glioma: an in vitro and in vivo study. Chin Med J (Eng). 2009; 122(14):1666-1673

17. Drevs J, Hofmann I, Hugenschmidt H, et al. Effects of PTK787/ZK 222584 , a specific inhibitor of vascular endothelial growth factor receptor tyrosine kinases, on primary tumor, metastasis, vessel density, and blood flow in a murine renal cell carcinoma model. Cancer Res. 2000; 60(17):4819-4824.

18. Lu J, Zhang K, Nam S, Anderson RA, Jove R, Wen W. Novel angiogenesis inhibitory activity in cinnamon extract blocks VEGFR2 kinase and downstream signaling. Carcinogenesis. 2010;31(3):481-488. 
19. Wen W, Lu J, Zhang K, Chen S. Grape seed extract inhibits angiogenesis via suppression of the vascular endothelial growth factor receptor signaling pathway. Cancer Prev Res (Phila). 2008;1(7):554-561.

20. Chamberlain MC. Bevacizumab for the treatment of recurrent glioblastoma. Clin Med Insights Oncol. 2011;5:117-129.

21. Banu NA, Daly RS, Buda A, Moorghen M, Baker J, Pignatelli M. Reduced tumour progression and angiogenesis in 1,2-dimethylhydrazine mice treated with NS-398 is associated with down-regulation of cyclooxygenase- 2 and decreased beta-catenin nuclear localisation. Cell Commun Adhes. 2011;18(1-2):1-8.

22. Ronca R, Benzoni P, Leali D, et al. Antiangiogenic activity of a neutralizing human single-chain antibody fragment against fibroblast growth factor receptor 1. Mol Cancer Ther. 2010;9(12):3244-3253.

23. Kim TH, Hur EG, Kang SJ, et al. NRF2 blockade suppresses colon tumor angiogenesis by inhibiting hypoxia-induced activation of HIF-1 $\alpha$. Cancer Res. 2011;71(6):2260-2275.

24. Skuli N, Monferran S, Delmas C, et al. Alphavbeta3/alphavbeta5 integrins-FAK-RhoB: a novel pathway for hypoxia regulation in glioblastoma. Cancer Res. 2009;69(8):3308-3316.

25. Wick W, Weller M, van den Bent M, Stupp R. Bevacizumab and recurrent malignant gliomas: a European perspective. J Clin Oncol. 2010; 28(12):e188-e189.

26. Bakowicz-Mitura K, Bartosz G, Mitura S. Influence of diamond powder particles on human gene expression. Surf Coat Technol. 2007; 201(13):6131-6135.

27. Liu KK, Cheng CL, Chang CC, Chao JI. Biocompatible and detectable carboxylated nanodiamond on human cell. Nanotechnology. 2007; 18(32):5102.

28. Prylutska SV, Burlaka AP, Prylutskyy YI, Ritter U, Scharff P. Pristine $\mathrm{C}(60)$ fullerenes inhibit the rate of tumor growth and metastasis. Exp Oncol. 2011;33(3):162-164.

29. Liu Z, Chen K, Davis C, et al. Drug delivery with carbon nanotubes for in vivo cancer treatment. Cancer Res. 2008;68(16):6652-6660.

30. Chaudhuri P, Harfouche R, Soni S, Hentschel DM, Sengupta S. Shape effect of carbon nanovectors on angiogenesis. ACS Nano. 2010;4(1): 574-582.

31. Murugesan S, Mousa SA, O’Connor LJ, Lincoln DW 2nd, Linhardt RJ. Carbon inhibits vascular endothelial growth factor- and fibroblast growth factor-promoted angiogenesis. FEBS Lett. 2007;581(6):1157-1160.

32. Mitura K, Chwalibog A, Sawosz E, et al. Nanoparticles of diamond do not stimulate angiogenesis in chicken embryo model. Paper presented at: 2nd International Workshop on Science and Applications of Nanoscale Diamond Materials; 2010 June 28-July 2; Zakopane, Poland.

33. Danilenko VV. Synthesizing and Sintering of Diamond by Explosion. Moscow: Energoatomizdat; 2003. Russian.

34. Kaczorowski W, Niedzielski P. Morphology and growth process of carbon films prepared by microwave/radio frequency plasma assisted CVD. Adv Eng Mater. 2008;10(7):651-656.
35. Seidlitz E, Korbie D, Marien L, Richardson M, Singh G. Quantification of anti-angiogenesis using the capillaries of the chick chorioallantoic membrane demonstrates that the effect of human angiostatin is agedependent. Microvasc Res. 2004;67(2):105-116.

36. Nagy JA, Vasile E, Feng D, et al. Vascular permeability factor/vascular endothelial growth factor induces lymphangiogenesis as well as angiogenesis. $J$ Exp Med. 2002;196(11):1497-1506.

37. McDonald DM, Baluk P. Significance of blood vessel leakiness in cancer. Cancer Res. 2002;62(18):5381-5385.

38. Tong RT, Boucher Y, Kozin SV, Winkler F, Hicklin DJ, Jain RK. Vascular normalization by vascular endothelial growth factor receptor 2 blockade induces a pressure gradient across the vasculature and improves drug penetration in tumors. Cancer Res. 2004;64(11):3731-3736.

39. Abdollahi A, Lipson KE, Sckell A, et al. Combined therapy with direct and indirect angiogenesis inhibition results in enhanced antiangiogenic and antitumor effects. Cancer Res. 2003;63(24):8890-8898.

40. Kalishwaralal K, Banumathi E, Ramkumarpandian S, et al. Silver nanoparticles inhibit VEGF induced cell proliferation and migration in bovine retinal endothelial cells. Colloids Surf B Biointerfaces. 2009; 73(1):51-57.

41. Gurunathan S, Lee KJ, Kalishwaralal K, Sheikpranbabu S, Vaidyanathan R, Eom SH. Antiangiogenic properties of silver nanoparticles. Biomaterials. 2009;30(31):6341-6350.

42. Sheikpranbabu S, Kalishwaralal K, Venkataraman D, Eom SH, Park J, Gurunathan S. Silver nanoparticles inhibit VEGF-and IL-1beta-induced vascular permeability via Src dependent pathway in porcine retinal endothelial cells. J Nanobiotechnology. 2009;7:8

43. Bhattacharya R, Mukherjee P, Xiong Z, Atala A, Soker S, Mukhopadhyay D. Gold nanoparticles inhibit VEGF165-induced proliferation of HUVEC cells. Nano Lett. 2004;4(12):2479-2481.

44. Karthikeyan B, Kalishwaralal K, Sheikpranbabu S, Deepak V, Haribalaganesh R, Gurunathan S. Gold nanoparticles downregulate VEGF-and IL-1 $\beta$-induced cell proliferation through Src kinase in retinal pigment epithelial cells. Exp Eye Res. 2010;91(5):769-778.

45. Kalishwaralal K, Sheikpranbabu S, BarathManiKanth S, Haribalaganesh R, Ramkumarpandian S, Gurunathan S. Gold nanoparticles inhibit vascular endothelial growth factor-induced angiogenesis and vascular permeability via Src dependent pathway in retinal endothelial cells. Angiogenesis. 2011;14(1):29-45.

46. Arvizo RR, Rana S, Miranda OR, Bhattacharya R, Rotello VM, Mukherjee P. Mechanism of anti-angiogenic property of gold nanoparticles: role of nanoparticle size and surface charge. Nanomedicine. 2011;7(5): 580-587.

47. Kemp MM, Kumar A, Mousa S, et al. Gold and silver nanoparticles conjugated with heparin derivative possess anti-angiogenesis properties. Nanotechnology. 2009;20(45):455104.
International Journal of Nanomedicine

\section{Publish your work in this journal}

The International Journal of Nanomedicine is an international, peerreviewed journal focusing on the application of nanotechnology in diagnostics, therapeutics, and drug delivery systems throughout the biomedical field. This journal is indexed on PubMed Central, MedLine, CAS, SciSearch ${ }^{\circledR}$, Current Contents ${ }^{\circledR} /$ Clinical Medicine,
Dovepress

Journal Citation Reports/Science Edition, EMBase, Scopus and the Elsevier Bibliographic databases. The manuscript management system is completely online and includes a very quick and fair peer-review system, which is all easy to use. Visit http://www.dovepress.com/ testimonials.php to read real quotes from published authors. 